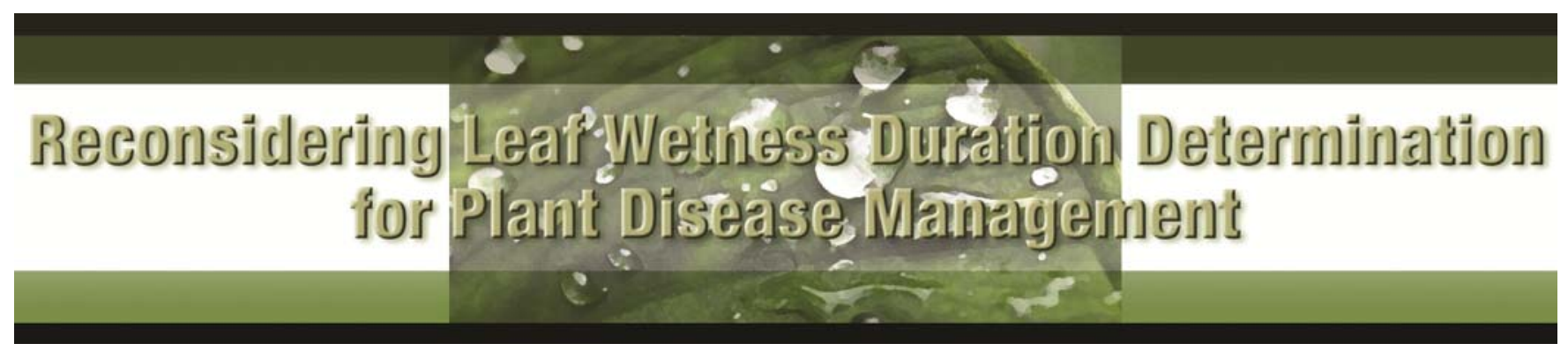

Tracy Rowlandson

Department of Geography, University of Guelph, Canada

Mark Gleason

Department of Plant Pathology and Microbiology, lowa State University, Ames

Paulo Sentelhas

Department of Biosystems Engineering - ESALQ, University of Sao Paulo, Brazil

Terry Gillespie

School of Environmental Sciences, University of Guelph, Canada

Carla Thomas

Department of Plant Pathology and National Plant Diagnostic Network, University of California, Davis

Brian Hornbuckle

Department of Agronomy, lowa State University, Ames

Relationships between leaf wetness and plant diseases have been studied for centuries. DeBary, in 1853, was one of the first researchers to associate the infection of potatoes by Phytophthora infestans with occurrence of free water on the plant canopy (69). Since then, the progress and risk of many bacterial, fungal, and oomycete diseases on a variety of crops have been linked to the presence of free water on foliage and fruit under temperatures favorable to infection (25). Whereas the rate parameters for infection or epidemic models have frequently been linked with temperature (e.g., degree-days) during the wet periods, leaf wetness periods of specific time duration are necessary for the propagule germination of most phytopathogenic fungi and for their penetration of plant tissues (28).

Figure 1 depicts relationships among leaf wetness duration (LWD) and air temperatures required for infection of several hosts by three different phytopathogenic fungi. Using these types of relationships, disease-warning systems were developed and are now being used by grower communities for a variety of crops. Examples of disease-warning systems based on LWD are shown in Table 1. As a component of Integrated Pest Management (IPM), disease-warning systems provide growers with information regarding the optimum timing for chemical or biological management practices based on weather variables (rainfall, humidity, LWD, air temperature) most suitable for pathogen dispersal or host infection (21). This approach contrasts with traditional calendar-based systems, which recommend sprays based on fixed calendar dates or phenological stages, rather than on dates determined by measures of environmental variables on infection and the levels of disease

Corresponding author: Tracy Rowlandson, Department of Geography, University of Guelph, Canada; E-mail: trowland@uoguelph.ca

http://dx.doi.org/10.1094/PDIS-05-14-0529-FE

(C) 2015 The American Phytopathological Society risk. Disease-warning systems can reduce the number of recommended sprays during periods when disease risk is low, but may also recommend more sprays than a calendar-based system when conditions are exceptionally disease-conducive (20). Although these systems are robust enough to permit some errors in the estimates or measurements of LWD, the need for highly accurate LWD data remains a priority to achieve the most efficient disease management.

\section{What Is Leaf Wetness?}

Leaf wetness is the presence of free water on the surface of a crop canopy. It results primarily from three sources: water that has been intercepted by the canopy during a rainfall or fog event; overhead irrigation; or dew, which can form on any surface of the crop

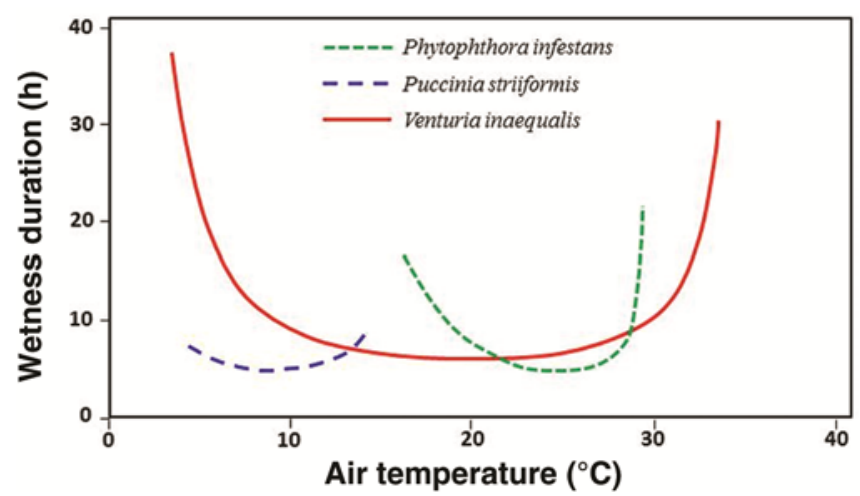

Fig. 1. Leaf wetness duration requirement based on temperature for infection by Phytophthora infestans, Puccinia striiformis, and Venturia inaequalis. Reprinted from Agriculture and Forest Meteorology, 151, S. Bregaglio, M. Donatelli, R. Confalonieri, M. Actuis, S. Orlandini, Multi-metric evaluation of leaf wetness models for large-area application of plant disease models, 1163-1172, Copyright 2011, with permission from Elsevier. 
canopy, mainly on leaves, on both their top and bottom sides. Dew forms where water vapor condenses on a surface; it is triggered when the temperature of a canopy surface drops below the dew point temperature of the surrounding air. There are two sources for water vapor. The first source, and most commonly referred to, is water vapor originating from the atmosphere above the canopy. Dew that forms from atmospheric water vapor is referred to as 'dewfall.' The second source of water vapor is the soil surface and profile; this proportionate contribution to the total dew amount is referred to as 'distillation' (distillation is also called 'dew rise' in the literature [27]).

Dew typically occurs during clear-sky nights, when long wave radiation is lost from the canopy to the atmosphere, resulting in cooling of the canopy. During overcast nights, clouds emit radiation downward toward the canopy, which partially offsets the canopy's losses to the atmosphere. This situation usually prevents the canopy from cooling to the dew point temperature of the canopy airspace, so dew usually cannot form. During a clear night, this downward radiation is reduced, and the canopy can cool sufficiently to promote dew deposition. Figure 2 shows a simple schematic of the energy balance for the Earth's surface during a night when dew typically occurs.

A light wind of less than $4 \mathrm{~ms}^{-1}$, measured at 10 -m height, in combination with clear skies and adequate atmospheric and/or soil moisture conditions, are ideal for maximum dew deposition (16). Wind speed is an important factor influencing dew deposition and evaporation. As a plant canopy cools to a dew point temperature, the air within the canopy becomes nearly saturated, with dew forming on leaves that are slightly cooler than the air (Fig. 3). If wind

Table 1. Examples of disease-warning systems that incorporate leaf wetness duration

\begin{tabular}{llc}
\hline Disease warning system & $\begin{array}{l}\text { Pathogen } \\
\text { group }\end{array}$ & Reference \\
\hline Apple scab & Fungi & 39 \\
Cedar apple rust & Fungi & 44 \\
Late blight (potato) & Oomycetes & 15 \\
Tomato early blight & Fungi & 48,20 \\
Strawberry anthracnose fruit rot & Fungi & 33 \\
Botrytis fruit rot (strawberry, grape) & Fungi & 34,4 \\
Alternaria brown spot (citrus) & Fungi & 47 \\
Brown spot of pear & Fungi & 32 \\
Sooty blotch and flyspeck (apple) & Fungi & 5,11 \\
Lettuce downy mildew & Oomycetes & 68 \\
Grape powdery mildew & Fungi & 24 \\
\hline
\end{tabular}

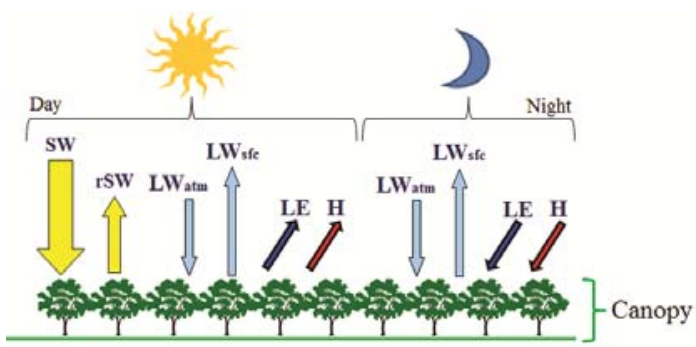

Fig. 2. Diagram of the surface energy budget. During the day, energy inputs to the surface include incoming solar radiation from the sun (SW) and longwave radiation contribution from the atmosphere (LWatm). Energy losses from the surface include reflected solar radiation (rSW), latent heat (LE), sensible heat $(\mathrm{H})$, and longwave radiation emitted by the surface (LWsfc). On a night when dew is forming, there is energy input from longwave radiation from the atmosphere (on a cloudy night, LWatm would increase); however, this amount is less than the longwave radiation output from the surface. Energy gain from latent heat indicates that there is energy provided to the surface through the condensation of water vapor. Sensible heat is an input as the temperature of the surface is less than the atmosphere above. The length and width of the arrows are for illustrative purposes only and are not accurately drawn in regard to the relative value of each energy component. speed is sufficiently high, drier air moves into the canopy, creating less humid conditions and reducing the likelihood of dew deposition. Similarly, if dew has already formed, the movement of drier air into a canopy will evaporate it from the foliar plant surfaces (14). Denser canopies are more prone to plant disease due to the reduced air circulation within the canopy that lengthens periods of LWD.

In some crops, guttation is also considered as a source of leaf wetness. Guttation occurs when water and solutes from inside the leaf are exuded to a leaf surface as a result of an osmotic process. In general, the contribution of guttation to the overall amount of free water on a leaf surface during wet periods is considered minimal, and is typically ignored (26); however, it may be important for the development of some diseases such as black rot of cabbage (7).

Unlike variables such as rainfall, temperature, or relative humidity (RH), LWD is not a standard meteorological measurement (35). Measurement of LWD has traditionally been confined to research wherein, for example, the risk of infection from a disease is related to the duration of wetness on a canopy. However, the implementation of disease-warning systems by growers has highlighted the need for easily accessible LWD data, which are typically not available from official weather station networks.

In many instances, LWD is measured using an in-field sensor, which detects the duration of leaf wetness resulting from rainfall, irrigation, and/or dew. When sensors are not available, LWD resulting from dew can be estimated, using models based on related weather variables that are obtained from weather station measurements. These models range from simplified empirical versions that require only one meteorological variable such as $\mathrm{RH}(57,67)$ to more complex ones that depend on variables such as hourly wind speed, net radiation, temperature, $\mathrm{RH}$, and in some instances information regarding soil type and moisture $(1,40,45,46,60)$. Some of the models based on physical principles can also estimate LWD considering rainfall or irrigation, when this information is available $(1,36)$.

A major limitation for the accurate and reliable determination of LWD is the lack of a standardized method for its calculation and use. The World Meteorological Organization (WMO) has standards in place for exposure and placement of all meteorological measurements; for example, temperature and $\mathrm{RH}$ are typically measured at $1.5 \mathrm{~m}$ above the ground, and wind speed at $10 \mathrm{~m}$. However, no such standards exist for LWD measurement, nor has a standard model been chosen for exclusive use (38). This lack of standardization makes comparison of research results difficult, and adds to the risk for growers in their adoption of disease-warning systems based on LWD.

\section{Evolution of Leaf Wetness Sensors}

LWD sensors have evolved from having no mechanical components to those based on electronics. Sensors are typically divided into three categories. The first group is static sensors. These sensors, such as the Duvdevani dew gauge, contain no mechanical or electronic components (12). The Duvdevani gauge consisted of a wooden block that was a standardized size and painted red. The blocks were placed outdoors, after sunset, at heights of 5, 25, 50, and $100 \mathrm{~cm}$ above the ground, in order for them to experience radiative cooling similar to that in a crop canopy $(17,51)$. The

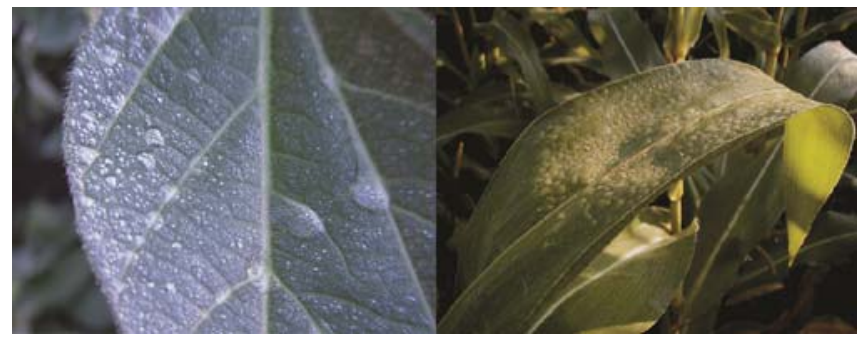

Fig. 3. Dew formation on a soybean (left) and maize (right) leaf. 
block was examined prior to sunrise, and the dew formation on the block was compared to a series of photographs. From these photographs, a scaling value was provided, which could be related back to the estimated amount of dew. An example of a dew scale photograph provided for the Duvdevani dew gauge is shown in Figure 4. This gauge was capable of indicating the formation of dew overnight, but could not provide a value for the period of dew duration; this is also the case for most static sensors (17).

The second category of sensors is mechanical. These sensors can record a change in weight of the sensor resulting from the presence of liquid water, or record a change in the length of a string (typically composed of hemp, human hair, or membrane). The De Wit Leaf Wetness recorder uses a hemp string that expands and lengthens when RH is high or during rainfall. The expansion and contraction of the string causes an ink pen to mark the duration of wet periods on a rotating chart $(28,49)$. Due to the close association between high RH and leaf wetness, a measurement of LWD can be obtained during wet periods (17). The ability to determine the duration of wet periods puts mechanical sensors at an advantage over static sensors (17). Figure 5 shows examples of mechanical LWD sensors.

The final category, and the most popular type of sensor currently in use, is the electronic sensor. Some of these sensors were designed to mimic the size of natural leaves; however, there is great variety in leaf shapes and sizes. Many electronic sensors consist of a printed grid of interlacing gold-plated copper wires (19). A known voltage is applied to the sensor; if water is present on the surface and bridges two of the interlaced wires, the circuit is complete, the resistance decreases, and a change in voltage occurs (6). Others measure the dielectric constant of the sensor surface (water

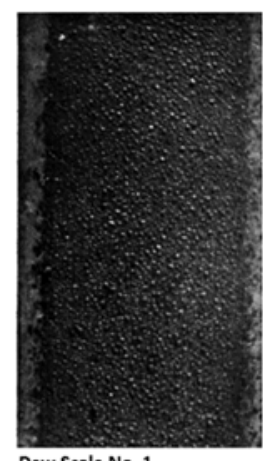

\begin{tabular}{|l|l|l|}
\hline & Dew Scale No. & \multicolumn{1}{|c|}{$\begin{array}{c}\text { Dew Amount } \\
(\mathrm{mm})\end{array}$} \\
\hline & 0 & Nodew \\
\hline & 1 & 0.025 \\
\hline & 2 & 0.045 \\
\hline & 3 & 0.07 \\
\hline & 4 & 0.10 \\
\hline & 5 & 0.14 \\
\hline & 6 & 0.18 \\
\hline & 7 & 0.21 \\
\hline & 3 & 0.25 \\
\hline & 9 & 0.30 \\
\hline & 10 & 0.35 \\
\hline
\end{tabular}

Fig. 4. Examples of dew scale photographs for the Duvdenvani dew gauge and the scale for converting to dew amount. Reprinted from Quarterly Journal of Royal Meteorological Society, 73, S. Duvedani, An optical method of dew estimation, 282296, Copyright 1947, with permission from John Wiley and Sons.

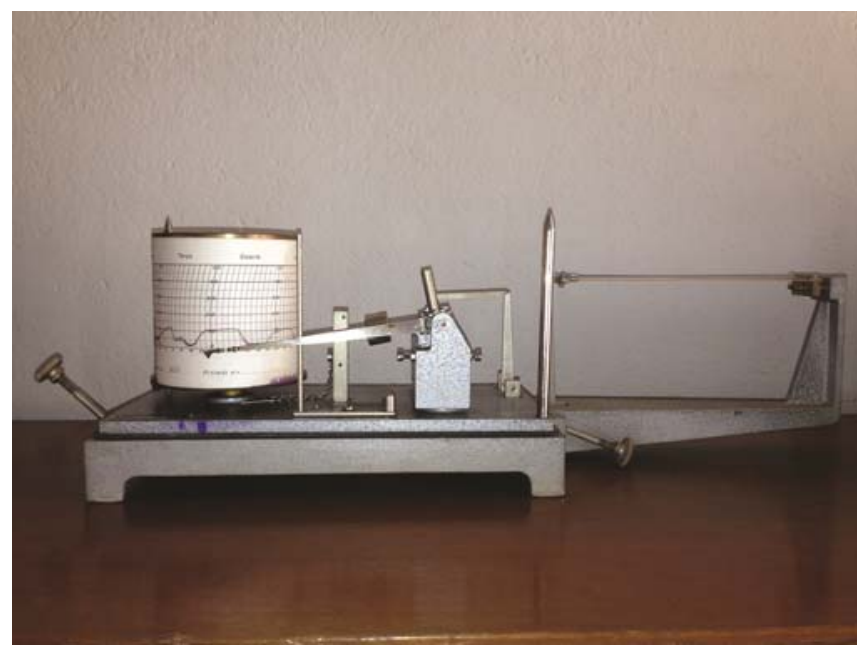

Fig. 5. Example of a mechanical sensor for leaf wetness duration estimates. having a much higher dielectric constant than air) (10). These sensors are connected to a datalogger that can record LWD at preselected time intervals during a growing season. Depending on the placement of the sensors within or near canopies, they are able to indicate the duration of wetness resulting from dew, rainfall, or irrigation events (17). There are several commercially available electronic LWD sensors on the market $(6,10,62)$, and many sensors have been produced in-lab for specific research purposes $(18,66)$ Figure 6 provides a sample of some commercially available electronic LWD sensors.

\section{Problems Associated with Using Electronic Leaf Wetness Sensors}

The problems associated with LWD measurement are usually not attributable to the sensors themselves, but rather to how the sensors are used. That is not to say sensors are problem-free, but when water is present on the surface of the sensor, the sensor will detect it. The question is: what does that sensor reading represent? Is it representative of LWD for a leaf, canopy, field, or region? Or, does it accurately represent only the sensor face, rather than plants? Many of the problems associated with accurate determination of LWD stem from the assumption-seldom verified-that the information obtained by a sensor is representative of the spatial scale at which the research or commercial spray timing is applied, whether at a single leaf, an apple canopy, a field of tomatoes, or an entire vineyard.

The most accurate estimates of LWD result from visual observation of water films and droplets on crop canopies. This task requires monitoring both the onset and dry-off of leaf wetness, and is often impractical due to cost constraints. Depending on the observation date, an observer may have to wait until after midnight or even later for dew to form. Although this may be thought of as a novel and worthwhile idea on the first night, the authors can attest that this feeling passes quickly. But a bigger problem is the definition of wetness. Is the onset of leaf wetness said to occur when the first droplet of water is seen on the crop canopy or when some portions of the leaves are wet? No set definition has been established, and comparison of LWD measured by sensors when compared to visual observations has used differing definitions. Dalla Marta et al. (8) indicated wetness began when $10 \%$ of the surface of a leaf was wet, whereas Lau et al. (31) assumed that it began when $50 \%$ of the sampled leaves exhibited wetness. Sentelhas et al. (59) tested LWD sensors over turfgrass and assumed that leaf wetness began at the first visible sign of droplets on a blade of grass.

Although electronic leaf wetness sensors have been the technology of choice for measuring LWD, pitfalls associated with the use

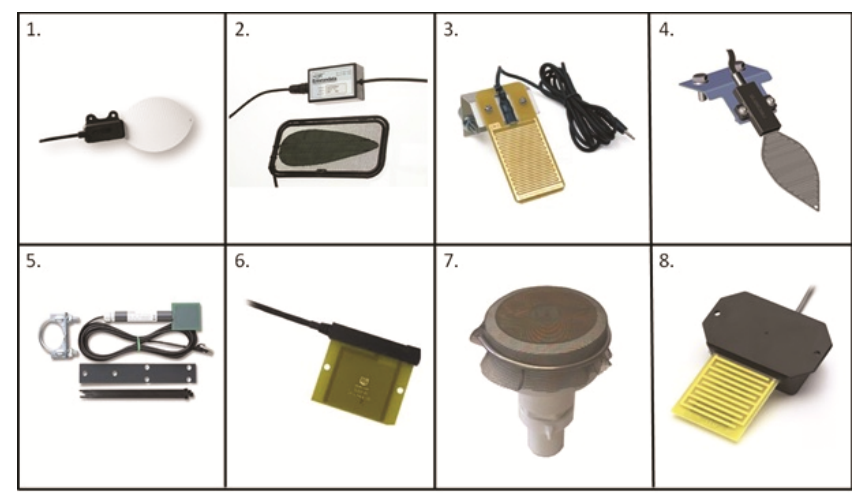

Fig. 6. Examples of commercially available leaf wetness sensors. 1. Decagon Devices (http://www.decagon.com/products/sensors/environmental-sensors/leaf-wet ness-sensor/); 2. Environdata (http://www.environdata.com.au/leaf_wetness_sens); 3. Spectrum Technologies, Inc. (http://www.specmeters.com/search/?key word=leaf \%20wetness\&perpage=12\&match=AND\&F_Sort=2); 4. Netsens (http:// www. netsens.it/en/leaf-wetness-sensor.php); 5. OnSet HOBO Dataloggers (http:// www. onsetcomp.com/products/sensors/leaf-wetness); 6. Campbell Scientific (http:// www. campbellsci.ca/237-I); 7. RainWise Inc. (http://www.rainwise.com/products/ detail. php?ID=6764); 8. Global Water (http://www.globalw.com/products/lw100.html). 
of these sensors are often overlooked. These include issues with painting sensors, placement of sensors, calibration, maintenance, and field accessibility. Several studies have been conducted on printed-grid electronic leaf wetness sensors to determine whether painting of the sensor surface is necessary. In the development of these sensors, it was noted that where small droplets of water accumulated between the wires on the sensor surface, but did not bridge the wires, low levels of wetness went undetected (9). Later, Gillespie and Kidd (19) found that painting the sensor surface influenced the duration of wetness measured. The same study found that the ideal paint color was a very light gray, as this color allows the sensor to mimic the thermal conditions of the leaves. Latex paint has been used most commonly because it allows water to penetrate through the paint surface for detection by the impedance grid. Further studies to determine how many coats of paint were required for an accurate estimation of leaf wetness reinforced the belief that sensors required painting, especially when attempting to detect duration of dew events $(31,61)$. Although the general consensus of the research community is that gridded resistance sensors require at least one coat of paint, many of these studies were conducted in differing crop canopies, with different sensor orientations relative to the plant stem axis, and in some cases, with different sensors entirely. A commonly used sensor for leaf wetness detection is the Campbell Scientific flat plate resistance sensor (237-L Leaf Wetness Sensor, Campbell Scientific, Logan, UT, USA). However, despite the findings regarding the impacts of painting on sensor sensitivity, this sensor is sold unpainted and has often been deployed that way.

The positioning of leaf wetness sensors in a crop canopy can profoundly influence their performance. Several studies have investigated how dew amount changes or varies within a crop canopy. For a maize canopy (Fig. 7), it was noted that the greatest dew amount occurs at approximately two-thirds of the canopy height, with dew amounts decreasing toward the bottom of the canopy (27). Most studies have indicated that maximum dew deposition occurs at approximately three-fourths of the canopy height $(37,38,50)$. Spatial heterogeneity in profiles of LWD has been estimated for maize, apple trees $(2,58)$, banana $(54)$, and soybeans (55). Figure 8 shows the spatial variability in LWD in an apple canopy resulting from dew events. However, substantial variability in dew amount and duration with canopy height seems to be limited to crops that are planted in dense rows or have dense canopies, such as apples. Vertical variability for LWD was not seen in crops such as coffee or grapes, where row spacing was broader and the

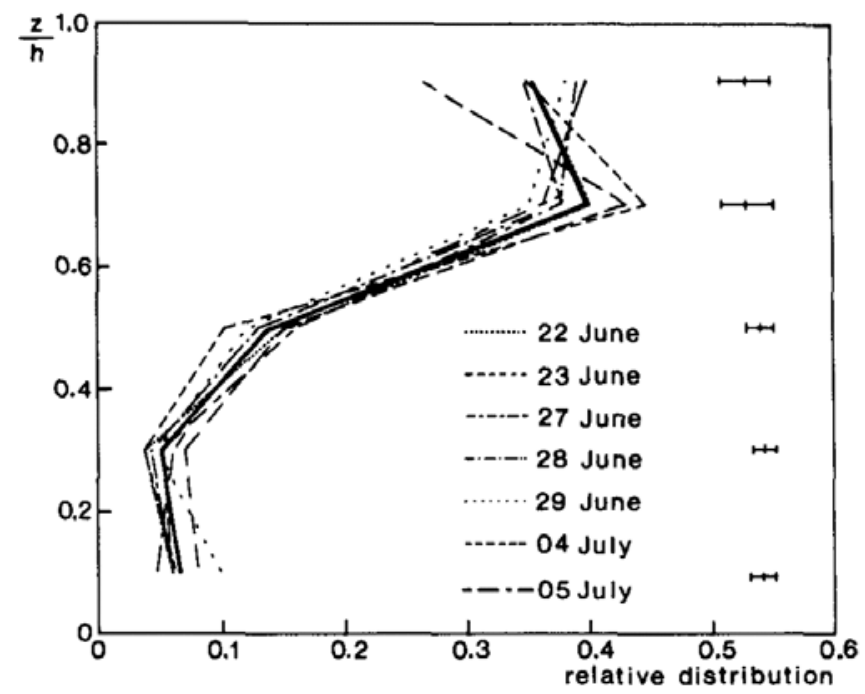

Fig. 7. Relative distribution of dew in a maize canopy for 7 dew days. The vertical is height above the soil surface, $z$, scaled by canopy height, $h$, with a value of $z / h=1$ indicating the top of the canopy. The horizontal axis is the relative distribution of the amount of dew. Source: (27). Copyright American Meteorological Society. Used with permission. plant density per row was lower (58). This difference may be due to the fact that with less dense planting, the entire plant experiences radiative cooling at nearly the same rate, and therefore dew deposition is more uniform. With dense planting, as traditionally seen with agronomic crops such as maize, the lower portion of the canopy is sheltered from experiencing the same amount of cooling as the upper canopy and therefore accumulates less dew.

Electronic leaf wetness sensors typically possess a single 'face' or surface where the printed sensing grid is located. Several studies have been conducted to determine how the sensor face should be exposed, placing it at angles of $0,15,30$, or $45^{\circ}$ from horizontal. In one study, sensors placed at 0 or $15^{\circ}$ had a longer measured LWD than visually observed LWD (59). A similar study conducted by Lau et al. (31) found deployment angle had no impact on the LWD measured by painted sensors. Despite the longer LWD seen by Sentelhas et al. (59), the error between the sensor and visual observations was less than an hour. The research community generally agrees that flat-plate leaf wetness sensors should not be oriented at $0^{\circ}$ as they collect too much water, and furthermore this is not a typical leaf angle in a crop canopy (31). However, due to a lack of standardization for the use of leaf wetness sensors, research has been conducted to compare or evaluate measurements of LWD for sensors deployed at a variety of angles.

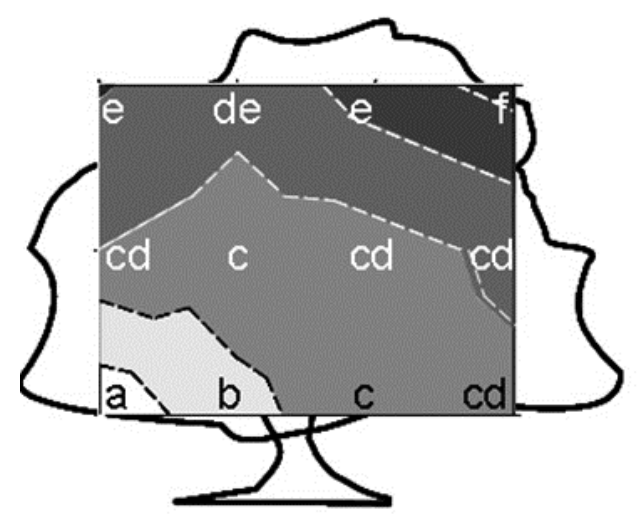

Fig. 8. Leaf wetness duration (LWD) variability in an apple orchard resulting from dew events. Dotted lines indicate a 1-h difference in LWD. Different letters indicate that the LWD is significantly different between regions (at $P<0.05$ ), with "a" representing the lowest LWD and "f" the highest. Reprinted from J. C. Batzer, M. L. Gleason, S. E. Taylor, K. J. Koehler, J. E. B. Monteiro, 2008, Plant Disease 92:164170.

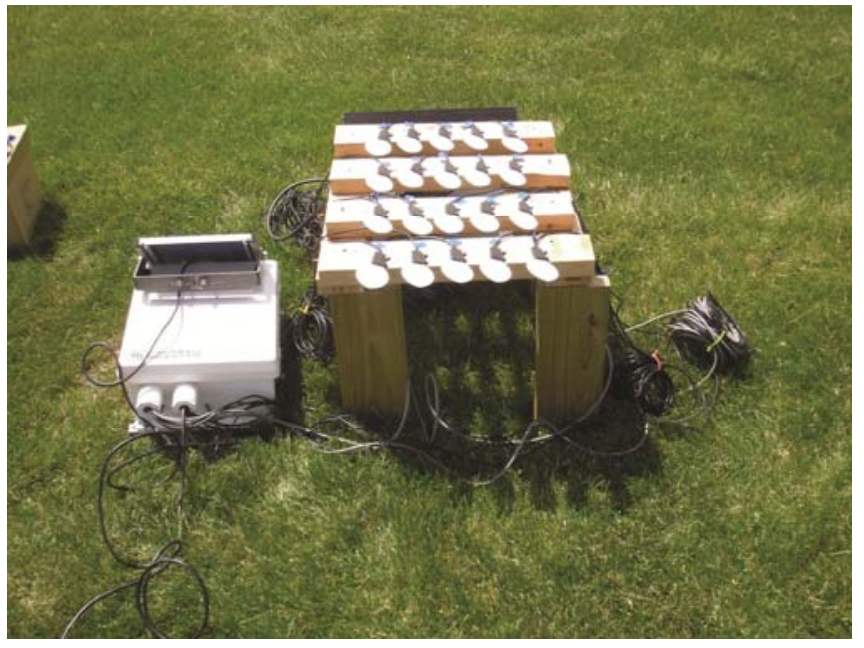

Fig. 9. Electronic wetness sensors deployed for calibration prior to installation in the field. The sensors are deployed at the same angle and compass orientation so that each sensor is exposed to as nearly the same environmental conditions (similar sensor view of sky and ground) as possible. 
Leaf wetness sensors require calibration. This is particularly important if multiple sensors are used in a research project or operational disease-warning system, where comparisons among the sensors are required. Prior to installation in the field, sensors should be placed adjacent to each other at the same height over a uniform, unobstructed land surface at the same angle to determine appropriate thresholds for wetness (Fig. 9). With electronic leaf wetness sensors that indicate wetness by a change in voltage, a threshold level must be determined in order to establish a boundary between periods that are assumed to be wet or dry. For example, output voltages above the threshold level indicate that the sensor is wet. Sensors that are used over multiple years must be recalibrated, as the paint and the sensing circuits can experience weathering or degradation, which may require adjustment of the wetness threshold. Magarey et al. (38) suggested that sensors should be repainted at least once per year. Although not stated, this could require the removal of previous paint applications. Santos et al. (53) compared cylindrical sensors originally designed for use in an onion crop (see Figure 10) in a laboratory and found little sensor-to-sensor variability when the same wetness threshold was applied to all sensors. However, when deployed over turfgrass, significant intersensor variability was observed and unique wetness thresholds were required for each sensor. This study highlights the importance of the recommendation that during calibration, sensors should be exposed to multiple rain and dew events to determine accurate threshold values.

Once electronic leaf wetness sensors are installed in a crop field (or nearby location), regular maintenance of them is required. Especially after rainfall, organic debris can be deposited on the surface of the sensor, which may influence the wetness threshold value. During periods of pollination, a layer of pollen can develop on a sensor surface and will require frequent cleaning for removal. Additionally, birds tend to perch on most field equipment, and leaf wetness sensors are no exception. Whether their perching alters the angle at which the sensor was placed, or whether they deposit excrement on the sensor (it will happen), regular inspection is required. The wires attaching sensors to dataloggers also attract rodents and ants, which can chew through them if the wires are exposed. For these and other reasons, significant portions of a data set can be lost unless data are being transmitted and observed in real time, and quality control of the data occurs in a timely matter. Magarey et al. (38) recommended maintenance visits every 2 weeks. The authors would argue that visits should be more frequent, when feasible, particularly for research projects. Debris on the leaf wetness sensors will lead to overestimation of LWD, which can result in unwarranted or false spray advisories.

Often wetness sensors are installed in the crop for which LWD data are required. Like other in-field sensors, cultivation, spraying,

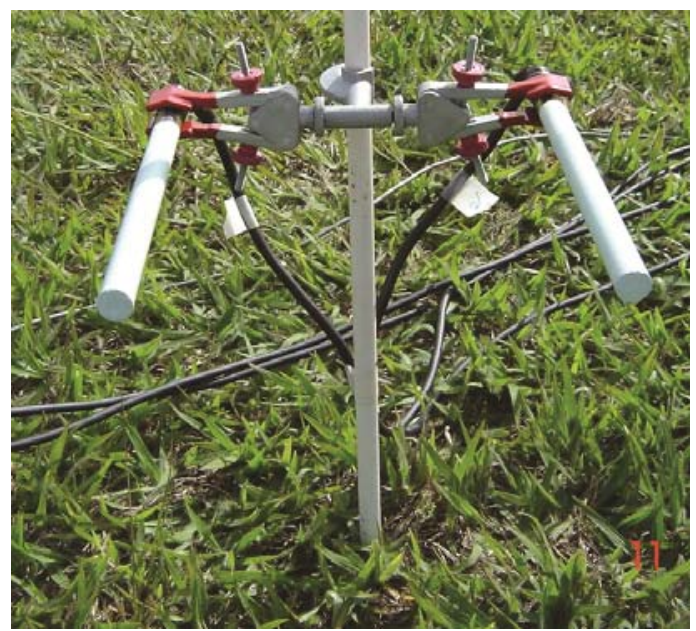

Fig. 10. Example of noncommercial cylindrical leaf wetness sensors. Photo: E. Santos. and the occasional desire of passersby to test their skill with firearms endanger wetness sensors.

\section{How Can We Minimize Use of Sensors but Still Obtain Leaf Wetness Duration Data?}

Measurement proximity. Can LWD data from nearby weather stations be used to estimate in-field LWD? One study compared the measurement of LWD within a crop canopy to measurements made by a sensor placed nearby (within a few hundred meters of the field) over a managed turfgrass surface (59). This study compared LWD measured by sensors placed at 'screen height' $(1.5 \mathrm{~m}$, the standard height at which temperature and $\mathrm{RH}$ measurements are made) to that measured at the apex of maize, cotton, and muskmelon canopies. The most precise agreement occurred for measurements at the apex of cotton and maize, with poorer agreement for measurements at the apex of a muskmelon canopy. However, when LWD was measured with the sensor placed at $30-\mathrm{cm}$ height over mowed turfgrass, the agreement with measurements taken at the apex of the maize and muskmelon canopies was very high (59). Other studies, such as by Sentelhas et al. (58) and Santos et al. (54), showed the same tendency. These results strengthen the idea that LWD could be measured near a crop canopy without having to install sensors in the canopy itself, and thereby avoid some of the variability inherent for in-field placements. There are potential problems associated with this approach, however. The turfgrass over which a sensor is placed requires maintenance, which may have to be done manually unless the sensor is removed. A sensor placed adjacent to a field will still require regular maintenance; however, access to it may be easier. Another possible problem is the vulnerability of an exposed sensor accessible to the general public and thereby susceptible to theft, incidental damage, or vandalism. Despite these potential problems with LWD sensors, their use has advanced our understanding of the role of foliar wetness in disease cycles and epidemic development.

Models. The use of LWD sensors can be costly and labor intensive. As an alternative, mathematical models offer the ability to simulate LWD using meteorological data available from most weather stations. No fewer than 20 models have been developed to estimate LWD $(25,30,36,43,45,46,57,60)$. These range from complex models based on an energy balance approach $(1,36,45,46,60)$ to models that require very few inputs and have been empirically derived $(57,67)$. Although they are typically divided into two categories, physical and empirical, some use aspects of both physical and empirical models. Many estimate the duration of dew periods, but some have been broadened to estimate wetness duration resulting from rainfall as well. Leaf wetness duration resulting from rainfall could persist for several days, and these models are necessary to estimate the amount of time required to evaporate water from a crop canopy (38). Such models typically fall under the category of physical models. Because they are based on the physics of leaf wetness formation and dissipation, they can be used in widely different geographical locations around the world with no adjustment to the model components. Physical models are classified as either one-source or two-source. One-source models consider dew formation from atmospheric water vapor contribution only $(25,45,46,52,60)$, whereas two-source models take into consideration the contribution of water vapor that originates from the soil surface as well $(1,43)$. These models require data for many meteorological variables, and two-source models also require information regarding the soil, such as texture and moisture. Due to the amount of data required to use these models, they are currently impractical for determining LWD for most researchers as well as most end users of disease-warning systems. However, with the increasing development of integrated, large data sets, metadata approaches that bring such variables into one model suggest the potential for this approach in the future.

Dew forms on a leaf when it cools to the dew point temperature, and the air immediately next to the leaf is saturated with water vapor ( $\mathrm{RH}$ at the leaf is $100 \%$ ) and condensation occurs. Relative humidity measurements at weather stations are made at standard 
screen height, which is above the canopy height for many crops. The conditions inside a crop canopy may be quite different. Although the RH measured is $<100 \%$ above the canopy, immediately next to leaves the air may be at saturation (40). Based on this concept, a simple empirical model was developed indicating that duration of leaf wetness is equal to the number of hours in which the $\mathrm{RH}$ measured 1.5 to $2.0 \mathrm{~m}$ above the ground is greater than or equal to $90 \%(23,60,63)$.

A limitation of empirical models, in contrast with physical models, is that empirical models are valid only for the region in which they were developed. If an empirical model is to be used in another part of the country or the world with different topography or climate, the empirical variables of the model need to be reinvestigated. For example, with an RH-based model it was found that a provisional threshold of $90 \%$ could be adjusted to $83 \%$ for a region in central Iowa, USA; $85 \%$ in Elora, Ontario, Canada; 92\% in Florence, Italy; and left at $90 \%$ for Piracicaba, Brazil (57). This regional recalibration of the threshold is important to minimize the risk of incorrectly estimating LWD.

Finally, some models are hybrids that are both physically and empirically based. In addition to modeling LWD from dew events, some hybrid models are also capable of estimating LWD from rainfall or irrigation events (29). One model, referred to by the acronym CART/SLD, was first developed by Gleason et al. (23) and then adjusted by Kim et al. (30). CART/SLD has inputs of wind speed, dew point depression (the difference between air temperature and dew point temperature), air temperature, and $\mathrm{RH}$. The CART/SLD model functions in a manner similar to a dichotomous taxonomic key in order to sort hourly weather data files into wetness categories of likely, unlikely, or uncertain. Predetermined thresholds for each variable are set; if the value of the variable is not within a specified range, the conditions for dew occurrence are not likely. The first variable examined is dew point depression. If the value is below the threshold, wind speed is examined, then RH. Dew duration is determined by two final equations, which require all the input variables, but also contain empirically derived coefficients (30). Another hybrid model, developed by Kim at al. (29), is based on fuzzy logic, dealing with reasoning that is approximate, rather than fixed and exact. Although an empirically based model, it incorporates physical concepts, requiring the input of vapor pressure deficit (VPD) (the difference between the vapor pressure when the air is saturated and the actual vapor pressure), net radiation, and wind speed. The model categorizes the inputs of VPD and net radiation as either high or low, and wind speed as either fast or slow. Rules of relationships are established by the user indicating the importance of each in the development of leaf wetness. These rules are combined, along with the values given to each input within their category (determined via a process called fuzzification), and an aggregated value between 0 and 1 is produced. Wetness is said to occur if the aggregated value is greater than 0.5 .

Whether a model is physical, empirical, or hybrid, one or more measured meteorological variables are required as inputs. The WMO has proposed standards that define exposure and placement of sensors in order to ensure standardization of measurement. Sensors installed for field experimentation or warning system implementation often do not meet these requirements, compromising the reliability of data. The data should be examined closely and regularly to ensure that sensors are fully operational. At the end of every cultivation season, sensors should be sent to the manufacturer for maintenance and recalibration; but this rarely occurs.

Sensor networks. If LWD data were needed for an agricultural region, a possible solution would be the installation of a network of leaf wetness sensors. In implementing a disease-warning system, a network could allow cost sharing among growers while still supplying accurate data. Challenges with this approach are to determine how many sensors are required to accurately represent a geographic region and to decide where the sensors should be placed. In a region with varying elevation and landscape, more sensors may be required than in flat, uniform terrain in order to capture the spatial variability in LWD. Ownership of the sensors and datalog- gers would have to be negotiated, and a system to ensure their calibration and maintenance would be required.

Some growers view on-site monitoring of environmental data for disease-warning systems as the most accurate option, and purchase the necessary instrumentation to make the measurements. However, in the authors' experience, such stations tend to become neglected. There is a common misconception that once a station has been purchased and installed, it will continue to function as required without regard for periodic maintenance and calibration. Gleason et al. (22) noted that weather stations are often installed incorrectly. Thermometers that are not properly shielded from the sun's radiation indicate air temperatures higher than actual, and nonleveled tipping bucket rain gauges underestimate the true amount of precipitation. These problems are in addition to the incorrect placement of LWD sensors. Regardless of how accurately a model could estimate LWD compared to sensor measurement or visual observations, if the data fed into the model are overly inaccurate, then so is the model output. Disease-warning systems do tend to err on the side of caution by overestimating disease risk; however, errors in LWD could translate to failure of a diseasewarning system, thereby reducing or even terminating the adoption of these programs.

Previous studies have examined statistical methods for estimating meteorological variables derived from weather stations, such as air temperature and $\mathrm{RH}$, in order to provide simulated measurements at a spatial resolution of a few hundred meters across large regions. Seem et al. (56) found that a regression analysis using data from three weather stations provided 85 to $95 \%$ accuracy in air temperature estimates for a region of approximately $300 \mathrm{~km}^{2}$. Using 2,000 automated weather stations in the western United States, Thomas et al. (64) found that there was high, positive correlation for air temperature among the weather stations, moderate correlation for RH and wind speed, but virtually no positive correlation for LWD. This distinction highlights the importance of understanding LWD values from differing mesoclimates at small spatial scales $(5$ to $20 \mathrm{~km}$ ). A model can provide a calibration tool for networks to account for changes in the microclimates of different crops (37), and provide the basis for the calibration of networks to multiple crops within a region.

Networks installed by a private company, government agency, academic institution, or consortium of these organizations provide much-needed weather information to growers. One such network in the western United States, near Salinas, CA, measures air temperature, RH, precipitation, solar radiation, wind speed, and LWD at weather stations sited to represent a series of different local climatic zones (64). Various companies that provide fee-based crop production advice disseminate the information collected within networks to growers. Many weather station networks in California, Washington, Oregon, Idaho, and Arizona are public/private partnerships in which private industry operates the networks, services and installs the equipment, and conducts quality control and interpretation of the weather data and warning system outputs for a fee or packaged in a crop care program (64). These networks also provide their weather data to researchers or grower groups in partnership arrangements. Similar networks operate in Ontario and Michigan. In Ontario, a network developed by Weather Innovations Inc. (www.weatherinnovations.com) provides daily maps of disease risk according to several disease-warning systems for fruit and vegetable growers in the province. Michigan State University operates Enviro-Weather (formerly, Michigan Automated Weather Network) (http://www.agweather.geo.msu.edu); this website provides daily reports at each network site regarding LWD. Although there are no formal advisories from specific disease-warning systems, hourly information on LWD, temperature, and RH is available for use as warning system inputs.

\section{Where Do We Go From Here?}

The research community has used leaf wetness sensors extensively to relate LWD to the risk of crop damage from various plant diseases. However, is the continued use of these sensors the best 
option? Calibration and maintenance of sensors are crucial to obtaining reliable LWD data. But these needs may be overlooked even within the research community, or the knowledge required for successful use of LWD sensors may be lacking. For growers, working with sensors and dataloggers is often not a practical or costeffective choice, even though many disease-warning systems have moved beyond the research community and are now available for implementation by growers.

Several studies compared both physical and empirical models to LWD sensors and visual observations, with encouraging results. Physical models provide accurate estimates of LWD, but their use is limited by the availability of the meteorological variables required, and if the quality of the meteorological data is poor, the results from the physical model are likely to be poor (29). A comparison between performance of leaf wetness sensors and a surrogate wetness threshold of $\mathrm{RH} \geq 90 \%$ was conducted for locations in the United States, Canada, Italy, and Brazil (Fig. 11). The model underestimated the duration of wetness for the sites in the United States, Canada, and Brazil, and overestimated duration in Italy. However, once adjustments were made to the RH threshold to provide a unique threshold for each location, the results had acceptable accuracy (57).

We suggest that the research and agricultural communities who have traditionally relied on data produced from LWD sensors instead use the simple, empirical model for LWD based solely on $\mathrm{RH}$. We make this suggestion for several reasons. The first is that it provides standardization for the estimation of LWD. This reduces the need to calibrate LWD sensors for which no consensus calibration standards exist, and circumvents questions about how LWD sensors should be oriented in a field and where they should be placed within the crop canopy. Second, RH is a standard meteorological variable measured at most automated weather stations, globally. Weather stations in the United States are required to meet the Federal Standards for siting Meteorological Sensors at Airports, which indicates that temperature and $\mathrm{RH}$ be measured at 1.5 $\mathrm{m}$ above the surface, which is the same exposure suggested by the WMO (65). However, it is necessary for suitable local RH thresholds to be established through visual observation. The authors recommend the technique described by Sentelhas et al. (57), where

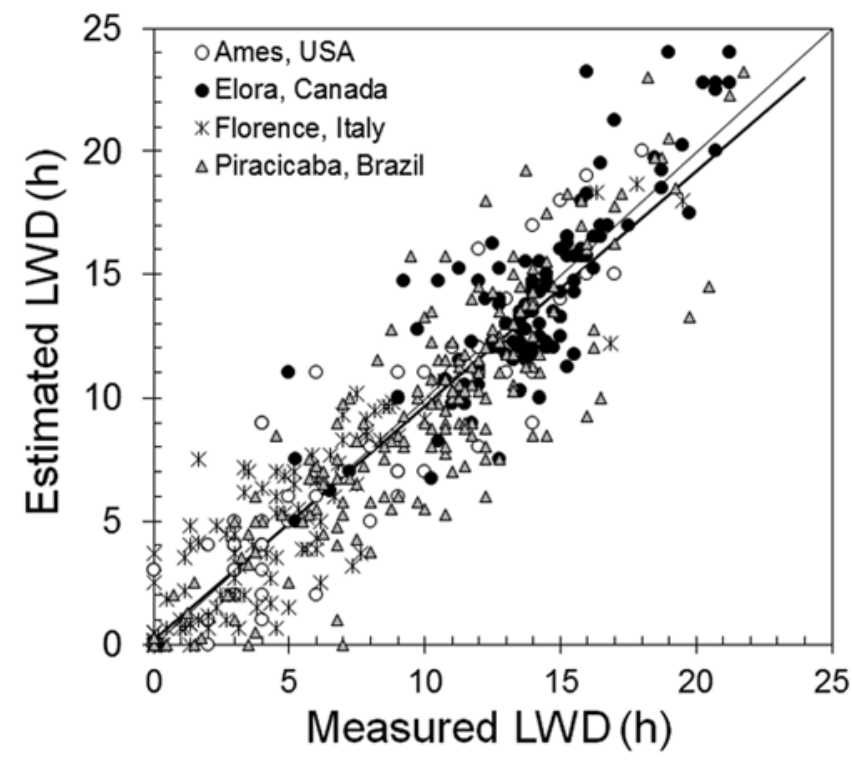

Fig. 11. Comparison of leaf wetness duration (LWD) measured by electronic leaf wetness sensors and the LWD estimated from the relative humidity $\geq$ threshold value for four locations. Thresholds were $83,85,92$, and $90 \%$ for: Ames, IA, USA; Elora, Ontario, Canada; Florence, Italy; and Piracicaba, Brazil, respectively. Reprinted from Agriculture and Forest Meteorology, 148, P. C. Sentelhas, A. Dalla Marta, S. Orlandini, E. A. Santos, T. J. Gillespie, M. L. Gleason, Suitability of relative humidity as an estimator of leaf wetness duration, 392-400, Copyright 2008, with permission from Elsevier. the onset of dew was defined as the first appearance of water droplets on the canopy, and dry-off is indicated when at least $80 \%$ of the canopy has dried. The RH thresholds can be expected to be within the range of 80 to $95 \%$ with higher value thresholds occurring for more humid regions. Hourly forecasts of $\mathrm{RH}$ can provide guidelines for appropriate observation times. To ensure that an accurate RH threshold is established, observations of wetness onset and dry-off should occur on at least five separate occasions.

There are approximately 1,600 automated weather stations providing data at hourly intervals in the United States (42) and more than 1,000 operating in Canada (Fig. 12) (13). In other countries, automated weather station networks are becoming more popular. In Brazil, for example, more than 500 weather stations report hourly data online through the National Institute of Meteorology website (www.inmet.gov.br). These sites are capable of providing the necessary hourly data for use of an appropriate RH threshold as a surrogate for LWD sensors. The maintenance of these sensors would be the responsibility of the meteorological services or Federal Aviation Authority, and no longer the responsibility of growers, extension personnel, or researchers. There are many other weather stations operational in North America which may adhere to the requirements of the $\mathrm{WMO}$ and provide the necessary $\mathrm{RH}$ measurements, but are not operated through governmental meteorological agencies.

Currently, in the United States, businesses from agricultural industry, combined with government and academia, have formed Ag Gateway (www.aggateway.org). This consortium is attempting to standardize meteorological data and provide a clear definition for each variable. This would include providing a definition for leaf wetness, which has not yet been defined by the research community.

This approach is not without its drawbacks, however. The data quality control and instrument repair may not happen quickly enough to maintain an uninterrupted disease-warning program. Additionally, the density of these stations is likely not sufficient in many countries for providing accurate $\mathrm{RH}$ and temperature data to all agricultural regions. Budget cuts to governmental agencies and academic institutions have reduced the number of sites for which near-real-time data are available, further decreasing the spatial density of current networks and the quality of the data due to reduced site visits and calibration. These constraints will prevent sole reliance on currently established automated weather stations, so some localized weather stations will be required in many regions. The need for additional measurements should be determined on a site-by-site basis, and the number of measurements will depend on such factors as site exposure, topography, and nearness to large bodies of water. Guidelines presented by the WMO can be used for exposure and siting of additional stations, but are currently not available for LWD sensors. Relative humidity sensors will still require annual calibration and maintenance checks, but these can likely be conducted on a schedule less frequent than required by LWD sensors, and can be conducted by the sensor manufacturer or trained technicians.

A more suitable alternative to dependence on weather station data would be the use of gridded weather products. Companies such as SkyBit, Inc. (www.skybit.com) and Fox Weather (fox weather2.com), as well as public organizations (www.uspest.org), provide temperature and $\mathrm{RH}$ values at a $1-$ to $10-\mathrm{km}$ grid, by downscaling global and regional models from the U.S. National Weather Service. The real-time mesoscale analysis (RTMA) produced by National Centers for Environmental Prediction (NCEP) for the United States provides hourly $2.5-\mathrm{km}$ resolution $\mathrm{RH}$ analyses. Fox Weather can provide estimates of $\mathrm{RH}$ at a $1-\mathrm{km}$ resolution that have shown high correlation between their products and station measurements (A. Fox, personal communication). The High Resolution Deterministic Prediction System (HRDPS) is currently an experimental operational product from Environment Canada, providing gridded $2.5-\mathrm{km}$ data for Canada and the northern portion of the United States. Relative humidity at these resolutions would provide the necessary information for the development 


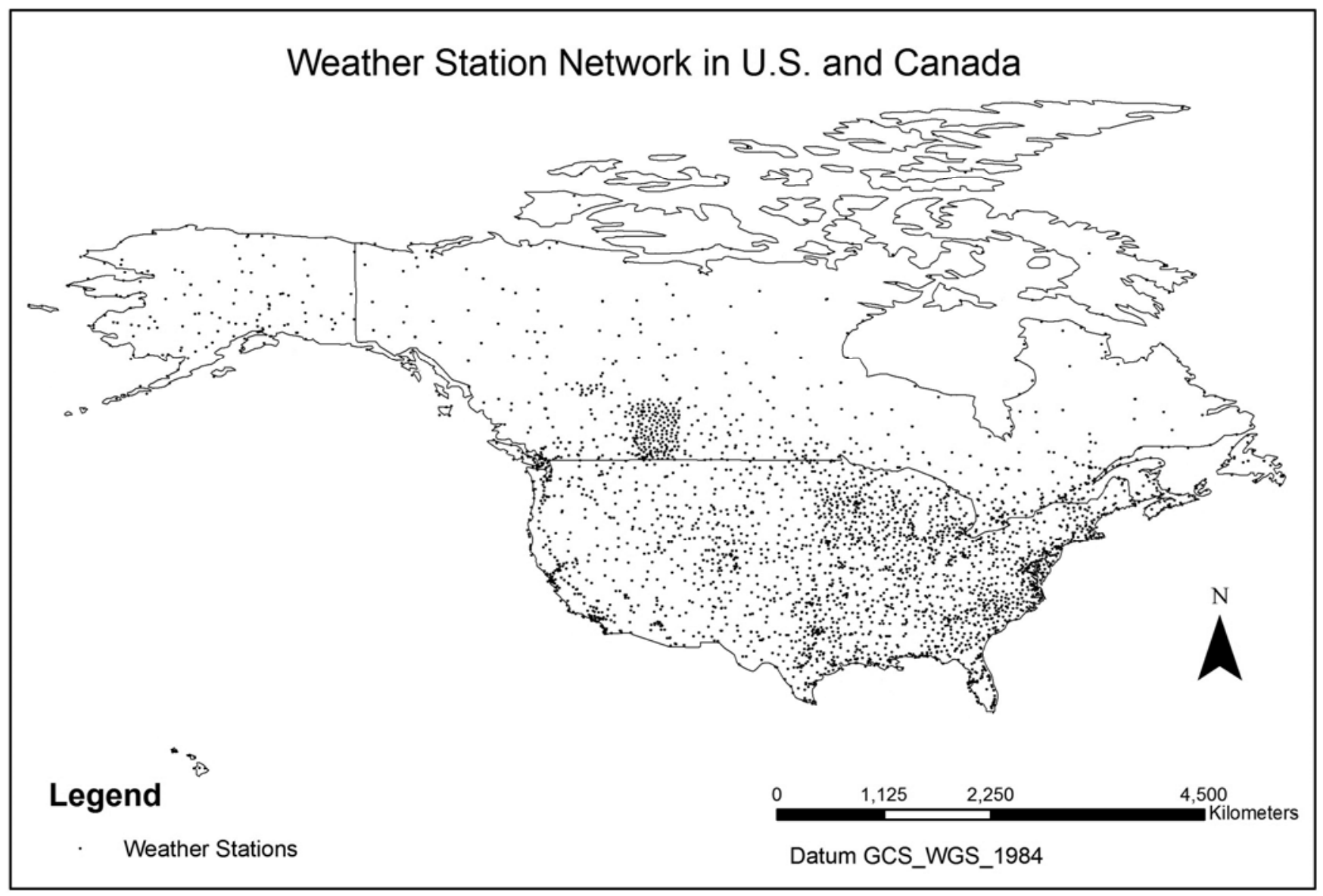

Fig. 12. Map of automated weather stations in the United States and Canada. Each dot represents an automated weather station capable of providing hourly temperature and relative humidity measurements (up to date as of 2013 for government monitored automated weather stations).

of disease-warning systems based on RH as opposed to LWD, at least for the United States. As gridded products advance to finer resolutions, field-specific estimates of $\mathrm{RH}$ could be possible.

Currently, LWD is being measured using a variety of electronic sensors, deployed at varying incidence angles and orientations, under different sensor face treatment regimens (i.e., painted versus unpainted), and sited at dissimilar canopy positions. LWD is also being estimated using a suite of models, either physical, empirical, or a hybrid of both concepts. There is no established standard for either sensor type or use, nor an agreed-upon model to estimate LWD. An empirical model, number of hours with $\mathrm{RH} \geq$ the locally adjusted threshold, has shown strong correlation with observed LWD. It requires the input of a single meteorological variable, which is a standard output for most weather stations around the world. This model would eliminate the need for reliance on LWD sensors, and also provide an international standard model from which required LWD estimates for disease-warning systems could be provided.

\section{Literature Cited}

1. Anderson, M., Norman, J., Meyers, T., and Diak, G. 2000. An analytical model for estimating canopy transpiration and carbon assimilation fluxes based on canopy light-use efficiency. Agric. For. Meteorol. 101:265-289.

2. Batzer, J. C., Gleason, M., Taylor, S. E., Koehler, K. J., and Monteiro, J. E. B. 2008. Spatial heterogeneity of leaf wetness duration in apple trees and its influence on performance of a warning system for sooty blotch and flyspeck. Plant Dis. 92:164-170.

3. Bregaglio, S., Donatelli, M., Confalonieri, R., Actuis, M., and Orlandini, S. 2011. Multi-metric evaluation of leaf wetness models for large-area application of plant disease models. Agric. For. Meteorol. 151:1163-1172.

4. Broome, J. C., English, J. T., Marois, J. J., Latorre, B. A., and Aviles, J. C. 1995. Development of an infection model for Botrytis bunch rot of grapes based on wetness duration and temperature. Phytopathology 85:97-102.

5. Brown, E. M., and Sutton, T. B. 1995. An empirical model for predicting the first symptoms of sooty blotch and flyspeck of apples. Plant Dis 79:1165-1168.

6. Campbell Scientific Inc. 2005. Model 237-L Leaf Wetness Sensors for MetaData1 User Manual. Campbell Scientific. 10 pp.

7. Carlton, W. M., Braun, E. J., and Gleason, M. 1998. Ingress of Clavibacter michiganensis subsp. michiganensis into tomato leaves through hydathodes. Phytopathology 88:525-529.

8. Dalla Marta, A., Magarey, R. D., and Orlandini, S. 2005. Modeling leaf wetness duration and downy mildew simulation on grapevine in Italy. Agric. For. Meteorol. 132:84-95.

9. Davis, D. R., and Hughes, J. E. 1970. A new approach to recording the wetting parameter by the use of electrical resistance sensors. Plant Dis 54:474-479.

10. Decagon Devices. 2009. Dielectric leaf wetness sensor Model LWS-1 Operators manual. Decagon Devices. 19 pp.

11. Duttweiler, K. B., Gleason, M., Dixon, P. M., Sutton, T. B., McManus, P. S., and Monteiro, J. E. B. 2008. Adaptation of an apple sooty blotch and flyspeck warning system for the Upper Midwest United States. Plant Dis. 92:1215-1222.

12. Duvdevani, S. 1947. An optical method of dew estimation. Q. J. R. Meteorol. Soc. 73:282-296.

13. Environment Canada National Climate Data and Information Archive. Available at: http://climate.weatheroffice.gc.ca/Welcome_e.html. Accessed June 12, 2013.

14. FAO. 1998. Introduction to evapotranspiration. In: Crop Evapotranspiration. Available at: http://www.fao.org/docrep/x0490e/x0490e04.htm. Accessed September 4, 2014.

15. Fry, W. E. 1982. Principles of Plant Disease Management. Academic Press, New York.

16. Garratt, J. R., and Segal, M. 1988. On the contribution of atmospheric moisture to dew formation. Bound. Layer Meteorol. 45:209-236.

17. Getz, R. 1992. World Meteorological Organization, Agricultural Meteorology CAgM Report No. 38: Report of the measurement of leaf wetness. $10 \mathrm{pp}$.

18. Gillespie, T. J., and Duan, R. 1987. A comparison of cylindrical and flat plate sensors for surface wetness duration. Agric. For. Meteorol. 40:61-70.

19. Gillespie, T. J., and Kidd, G. E. 1978. Sensing duration of leaf moisture retention using electrical impedance grids. Can. J. Plant Sci. 58(1):179-187. 
20. Gillespie, T. J., Srivastava, B., and Pitblado, R. 1993. Using operational weather data to schedule fungicide sprays in tomatoes in Southern Ontario, Canada. Can. J. Appl. Meteorol. 32:567-573.

21. Gleason, M. L., Duttweiler, K. B., Batzer, J. C., Taylor, S. E., Sentelhas, P. C., Monteiro, J. E. B., and Gillespie, T. J. 2008. Development and validation of an empirical model to estimate the duration of dew periods. Sci. Agric. 65.

22. Gleason, M. L., Duttweiler, K. B., Batzer, J. C., Taylor, S. E., Sentelhas, P. C., Monteiro, J. E. B. A., and Gillespie, T. J. 2008. Obtaining weather data for input to crop disease-warning systems: Leaf wetness duration as a case study. Sci. Agric. 65:76-87.

23. Gleason, M. L., Taylor, S. E., Loughin, T. M., and Koehler, K. J. 1994. Development and validation of an empirical model to estimate the duration of dew periods. Plant Dis. 78:1011-1016.

24. Gubler, W. D., Rademacher, M. R., Vasquez, S. J., and Thomas, C. 1999. Control of powdery mildew using the UC Davis powdery mildew risk index. Available at: http://www.apsnet.org/publications/apsnetfeatures/ pages/UCDavisRisk.aspx. Accessed September 4, 2014

25. Huber, L., and Gillespie, T. J. 1992. Modeling leaf wetness in relation to plant disease epidemiology. Physics (College Park Md.) 30:553-577.

26. Jacobs, A. F., Van Pul, A., and El-Kilani, R. M. M. 1994. Dew formation and drying process within a maize canopy. Bound. Layer Meteorol. 69:367-378

27. Jacobs, A. F., Van Pul, A., and Van Duken, A. 1990. Similarity moisture dew profile within a corn canopy. J. Appl. Meteorol. 29.

28. Jones, A. L. 1986. Role of wet periods in predicting foliar diseases. Pages 87-100 in: Plant Disease Epidemiology. K. J. Leonard and W. E. Fry, eds. MacMillan Publishing Company, New York.

29. Kim, K. S., Taylor, S. E., and Gleason, M. L. 2004. Development and validation of leaf wetness duration model using a fuzzy logic system. Agric. For. Meteorol. 127:53-64.

30. Kim, K. S., Taylor, S. E., Gleason, M. L., and Koehler, K. J. 2002. Model to enhance site-specific estimation of leaf wetness duration. Plant Dis. 86:179185.

31. Lau, Y., Gleason, M. L., Zriba, N., Taylor, S. E., and Hinz, P. N. 2000. Effects of coating, deployment angle, and compass orientation on performance of electronic wetness sensors during dew periods. Plant Dis. 84:192-197.

32. Llorente, I., Vilardell, P., Bugiani, R., Gerardi, I., and Montesinos, E. 2000. Evaluation of BSPcast disease-warning system in reduced fungicide use programs for management of brown spot of pear. Plant Dis. 84:631-637.

33. Mackenzie, S. J., and Peres, N. A. 2012. Use of leaf wetness and temperature to time fungicide applications to control anthracnose fruit rot of strawberry in Florida. Plant Dis. 96:522-528

34. Mackenzie, S. J., and Peres, N. A. 2012. Use of leaf wetness and temperature to time fungicide applications to control Botrytis fruit rot of strawberry in Florida. Plant Dis. 96:529-536.

35. Madeira, A. C., Kim, K. S., Taylor, S. E., and Gleason, M. L. 2002. A simple cloud-based energy balance model to estimate dew. Agric. For. Meteorol. 111:55-63.

36. Magarey, R. D., Russo, J. M., and Seem, R. C. 2006. Simulation of surface wetness with a water budget and energy balance approach. Agric. For. Meteorol. 139:373-381.

37. Magarey, R. D., Seem, R. C., Russo, J. M., Zack, J. W., Waight, K. T., Travis, J. M., and Oudemans, P. V. 2001. Site-specific weather information without on-site sensors. Plant Dis. 85:1216-1226.

38. Magarey, R. D., Seem, R. C., Weiss, A., and Gillespie, T. J. 2005. Estimating surface wetness on plants. Pages 199-226 in: Micrometeorology in Agricultural Systems. J. L. Hatfield and J. M. Baker, eds. American Society of Agronomy, Madison, WI.

39. Mills, W. D. 1947. How to use the time-temperature chart of apple scab control. Proc. N.Y. State Hortic. Soc. 199-202.

40. Monteith, J. L. 1957. Dew. Q. J. R. Meteorol. Soc. 83:322-341.

41. Montone, V., Fraisse, C., Peres, N., and Sentelhas, P. 2013. Evaluating leaf wetness duration models and their influence on a disease-warning system for strawberry. Poster session presetned at: American Society of Agronomy, Tampa, FL.

42. National Climate Data Center Land-Based Datasets and Products. Available at: http://www.ncdc.noaa.gov/data-access/land-based-station-data/landbased-datasets. Accessed July 6, 2014

43. Norman, J. M. 1979. Modeling the complete crop canopy. Pages 249-277 in: Modification of the Aerial Environment of Plants. B. J. Barfied and J. F. Gerber, eds. ASAE-Monog. Am. Soc. Agric. Eng., St. Joseph, MI.

44. Pearson, R., Aldwinckle, H. S., and Seem, R. C. 1977. Teliospore germination and basidiospore formation in Gymnosporangium juniperi- virginianae: A regression model of temperature and time effects. Can. J. Bot. 55:2832-2837.

45. Pedro Junior, M. J., and Gillespie, T. J. 1982. Estimating dew duration I Utilizing standard weather station data. Agric. Meteorol. 25:283-296.

46. Pedro Junior, M. J., and Gillespie, T. J. 1982. Estimating dew duration II Utilizing standard weather station data. Agric. Meteorol. 25:297-310.

47. Peres, N. A., and Timmer, L. W. 2006. Evaluation of the Alter-Rater model for spray timing for control of Alternaria brown spot of Murcott tangor in Brazil. Crop Prot. 25:454-460.

48. Pitblado, R. E. 1992. The development and implementation of TOM-CAST. University of Guelph Ridgetown College of Agricultural Technology.

49. Post, J. J. 1959. Het instrumentarium voor het bepalim van infecteperioden. Meded Dir. Tuinbouw Neth. 22:365-371.

50. Potratz, K. J., Gleason, M. L., Hockmuth, M. L., Parker, S. K., and Pearston, G. 1994. Testing the accuracy and precision of wetness sensors in a tomato field and on turfgrass. J. Iowa Acad. Sci. 101:56-60.

51. Rao, P. 2008. Agricultural Meteorology. Asoke K. Ghosh Prentice Hall of India, New Delhi.

52. Rao, P., Gillespie, T. J., and Schaafsma, A. 1998. Estimating wetness duration on maize ears from meteorological observations. Can. J. Soil Sci. 78:149-154.

53. Santos, E. A., Sentelhas, P. C., Gillespie, T. J., and Lulu, J. 2008 Performance of cylindrical leaf wetness duration sensors in a tropical climate condition. Sci. Agric. (Piracicaba, Braz.) 65:1-9.

54. Santos, E. A., Sentelhas, P. C., Pezzopane, J. E. M., Angelocci, L. R., and Monteiro, J. E. B. 2008. Spatial variability of leaf wetness duration in cotton, coffee and banana crop canopies. Sci. Agric. (Piracicaba, Braz.) 65:18-25.

55. Schmitz, H., and Grant, R. 2009. Precipitation and dew in a soybean canopy: Spatial variations in leaf wetness and implications for Phakospora pachyrhizi infection. Agric. For. Meteorol. 149:1621-1627.

56. Seem, R. C., Magnus, A. H., and Hjonnewaag, V. 1991. High resolution weather information for plant protection. EPPO Bull. 21:355-364

57. Sentelhas, P. C., Dalla Marta, A., Orlandini, S., Santos, E. A., Gillespie, T. J., and Gleason, M. L. 2008. Suitability of relative humidity as an estimator of leaf wetness duration. Agric. For. Meteorol. 148:392-400.

58. Sentelhas, P. C., Gillespie, T. J., Batzer, J. C., Gleason, M. L., Monterio, J. E. B. A., Pezzopane, J. E. M., and Pedro Junior, M. J. 2005. Spatial variability of leaf wetness duration in different crop canopies. Int. J. Biometeorol. 49:363-370.

59. Sentelhas, P. C., Gillespie, T. J., Gleason, M. L., Monteiro, J. E. B., and Helland, S. T. 2004. Operational exposure of leaf wetness sensors. Agric. For. Meteorol. 126:59-72.

60. Sentelhas, P. C., Gillespie, T. J., Gleason, M. L., Monteiro, J. E. B. A., Pezzopane, J. R. M., and Pedro Junior, M. J. 2006. Evaluation of a PenmanMonteith approach to provide "reference" and crop canopy leaf wetness duration estimates. Agric. For. Meteorol. 141:105-117.

61. Sentelhas, P. C., Monteiro, J. E. B. A., and Gillespie, T. J. 2004. Electronic leaf wetness duration sensor: Why it should be painted. Int. J. Biometeorol. 48:202-205.

62. Spectrum Technologies. 2011. WatchDog Leaf Wetness Sensor Product Manual. Spectrum Technologies. 4 pp.

63. Sutton, J. C., Gillespie, T. J., and Hildebrand, P. D. 1984. Monitoring weather factors in relation to plant disease. Plant Dis. 68:78-84

64. Thomas, C. S., Skinner, P. W., Fox, A. D., Greer, C. A., and Gubler, W. 2002. Utilization of GIS/GPS-based information technology in commercial crop decision making in California, Washington, Oregon, Idaho, and Arizona. J. Nematol. 34:200-206.

65. U.S. Department of Commerce. 1994. Federal Standard for Siting Meteorological Sensors in Airports. 23 pp. Accessible at: http://www.ofcm. gov/siting/pdf/fcm-s4-1994(Siting).pdf. Accessed September 4, 2014.

66. Wei, Y. Q., Bailey, B., and Stenning, B. 1995. A wetness sensor for detecting condensation on tomato plants in greenhouses. J. Agric. Eng. Res. 61:197-204.

67. Wichink Kruit, R., van Pul, A., Jacobs, A., and Heusinkveld, B. 2004 Comparison between four methods to estimate leaf wetness duration caused by dew on grassland. In: Conference on Agricultural and Forest Meteorology. American Meteorological Society, Vancouver.

68. Wu, B. M., van Bruggen, A. H. C., Subbarao, K. V., and Pennings, G. G. H 2001. Validation of weather and leaf wetness forecasts for lettuce downy mildew warning system. Can. J. Plant Pathol. 23:371-383.

69. Yarwood, C. E. 1978. Water and the infection process. Pages 141-173 in: Water Deficits and Plant Growth. T .T. Kozlowki, ed. Academic Press, New York. 


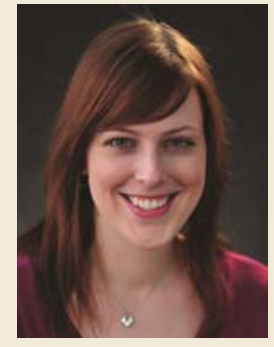

Tracy Rowlandson

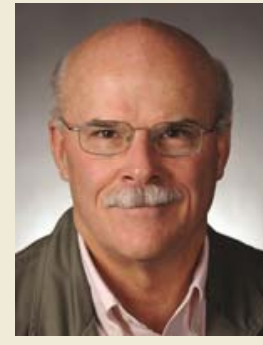

Mark Gleason

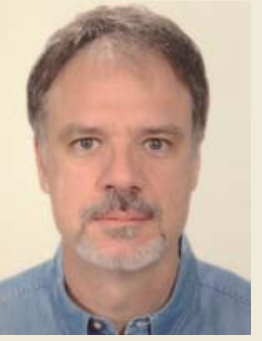

Paulo Sentelhas

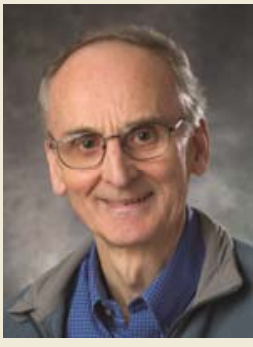

Terry Gillespie

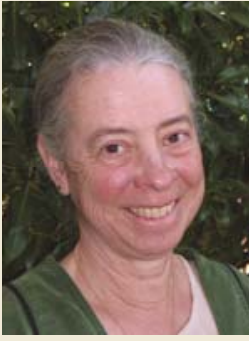

Carla Thomas

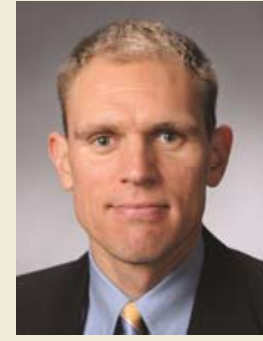

Brian Hornbuckle
Dr. Rowlandson received a B.Sc. in environmental science from the University of Guelph in 2003 and a M.Sc. degree in agricultural meteorology from the University of Guelph in 2006. After completing her M.Sc. degree, Tracy worked in private industry providing services to growers and governmental agencies regarding integrated pest management. She completed her Ph.D. degree in agricultura meteorology in the Department of Agronomy at lowa State University in 2011. Currently, she is a research scientist in the Department of Geography at the University of Guelph. Her research interests include investigating the impact of vegetation and soil management practices on soil moisture retrieval using passive and active microwave remote sensing.

Dr. Gleason is a professor in the Department of Plant Pathology and Microbiology at lowa State University. Gleason's research, teaching, and outreach currently focus on bacterial wilt of cucurbits, sooty blotch and flyspeck of apple, and anthracnose fruit rot of strawberry. He is an APS Fellow, the current Editor-in-Chief of Plant Disease, and a leader of the Midwest Weather Working Group.

Dr. Sentelhas is an associate professor in agrometeorology in the Department of Biosystems Engineering at ESALQ in the University of São Paulo, Brazil. Sentelhas's research and teaching is focused on agrometeorology and its relationship with plant diseases. Currently, he is conducting several studies about the use of disease warning systems for soybean Asian rust, coffee rust, grape mildew, and citrus post bloom drop fruit.

Dr. Gillespie is a professor emeritus in the School of Environmental Science at the University of Guelph, Canada. His research program has included the measurement and modeling of leaf wetness duration for use in understanding the relationships between weather and fungal plant diseases, and for use in scheduling disease control measures. His other main research interests have included interactions between plants and air quality, and meteorological aspects of outdoor human comfort.

Ms. Thomas serves as the chair of the Epidemiology Subcommittee for the National Plant Diagnostic Network (NPDN). She also serves as associate director at the Western Regional Center of the NPDN at the Department of Plant Pathology, University of California, Davis. Ms. Thomas received her B.S. degree in horticulture in 1981 and her M.S. in botany and plant pathology in 1984 from Michigan State University. Her research and project management interests are in weather-based decision support models and their operationalization. She has conducted research and facilitated implementation of weatherbased decision support for plant health management in over nine countries working with public and private sector organizations. She and her collaborators, including members of the Western IPM Weather Work Group, conducted pioneering work on the use of multistate weather networks and other meteorological and climatological data sources for plant health decision support systems.

Dr. Hornbuckle received the Sc.B. degree in electrical engineering (systems) from Brown University, Providence, $\mathrm{RI}$, in 1994, the M.A. degree in secondary education (science) from the University of Mississippi, Oxford, in 1996, the M.S.E. degree in electrical engineering (electromagnetics and signal processing) from the University of Michigan, Ann Arbor, in 1997, and the Ph.D. degree in electrical engineering and atmospheric science (geoscience and remote sensing), also from the University of Michigan, in 2003. His research interests center around land surface processes in agricultural ecosystems, with particular emphasis on the use of microwave radiometry to monitor the movement of water among the soil, vegetation canopy, and atmosphere. 